\title{
Vascular Lesion of Neck with Lymphatic Cyst of the Right Parapharyngeal Space
}

\author{
Bharath Rao ${ }^{1}$ and Azeem Mohiyuddeen ${ }^{2}$ \\ ${ }^{1}$ Specialist ENT, Amber Clinics, Al Rigga Road, Dubai, UAE. Formerly Associate Consultant in ENT, Fortis Hospitals, BG Road, Bangalore, India \\ ${ }^{2}$ Professor in ENT, Sri Devaraj Urs Medical College and Hospital, Kolar, India
}

Submission: April 22, 2017; Published: May 04, 2017

*Corresponding author: Bharath Rao, Specialist ENT, Amber Clinics, Al Rigga Road, Dubai ,UAE, Email: drbharathns@gmail.com

\begin{abstract}
Vascular lesions and lymphatic cyst of head and neck are a diverse group of conditions which can be of congenital or acquired nature. They have marked predilection for head and neck region. They often present a diagnostic and treatment dilemma. Here we present a case report where a patient presented with vascular lesion of external jugular venous system and submandibular gland with unilateral parapharyngeal lymphatic cyst.
\end{abstract}

\section{Introduction}

Vascular malformations of external jugular system are rare(1). Vascular tumours of the head and neck region comprise a heterogenous group of lesions which may have different histology, clinical features and different treatment options. Included in this group are benign and malignant tumours and non neoplastic masses. Here we present three different conditions in a male patient, comprising of vascular malformation of the external jugular vein with vascular tumour of the submandibular gland. And a lymphatic cyst of the parapharyngeal space, all occurring on the one side.

\section{Case Report}

A 47 year old moderately built patient came to ENT OPD with a history of a swelling on the right side of the neck in submandibular area since 2 weeks. He noticed it as an abrupt swelling appeared over 3-4 days time. He complained of a bulge over the right side of the neck which increased in size on performing valsalva manoeuvre. Preliminary ENT examination showed right submandibular swelling of about $3 \mathrm{x} 4 \mathrm{~cm}$ with cystic consistency. No intra-oral swelling seen. A compressible neck swelling seen on the right side laterally over the sternomastoid muscle, engorged on valsalva manoeuvre. Bluish pigmentation of skin was seen over the swelling. No bruit was heard. Laryngoscopy revealed normal laryngeal inlet and mobile bilateral vocal cords. No palpable cervical lymph nodes. MRI was taken which showed irregular lobulated right parapharyngeal lesion superiorly extending upto skull base abutting the jugular foramen eroding the clivus, inferiorly extending upto the hyoid arch. CT angiography shows poor internal vascularity of the lesion. Another well circumscribed nodular lesion in the right submandibular gland with internal hemorrhage. Lesion was isointense with hemorrhagic changes on T1 and turns heterogeneously hyperintense on the T2, FNAC of the submandibular lesion was inconclusive.

Patient was planned for tumour excision by transcervical approach under general anaesthesia under the guidance of second author. Consent for tracheostomy and mandibulotomy was taken (Figures 1 - 5).

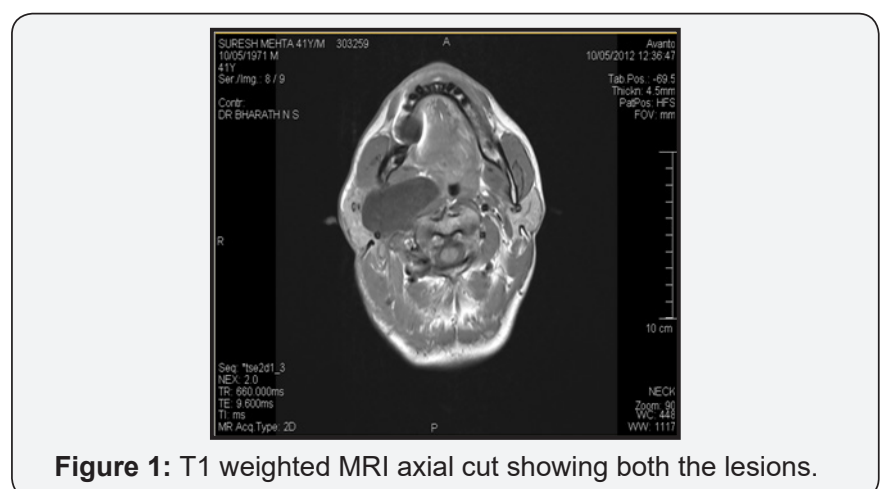

Figure 1: T1 weighted MRI axial cut showing both the lesions. 


\section{Global Journal of Otolaryngology}

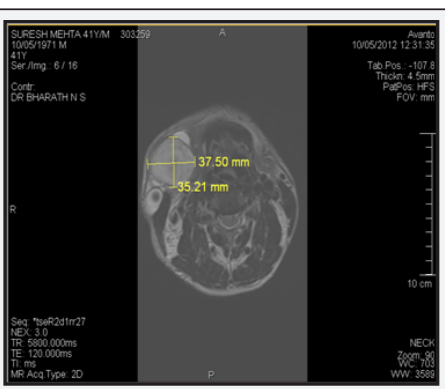

Figure 2: T2 weighted MRI axial cut showing right submandibular vascular lesion.

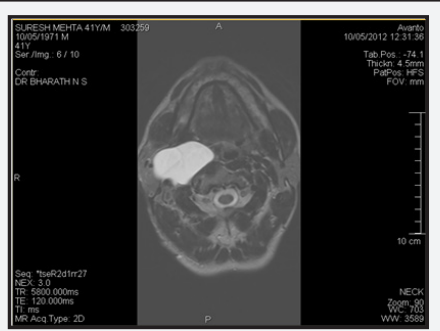

Figure 3: T2 weighted MRI axial cut showing right sided parapharyngeal lymphatic lesion.

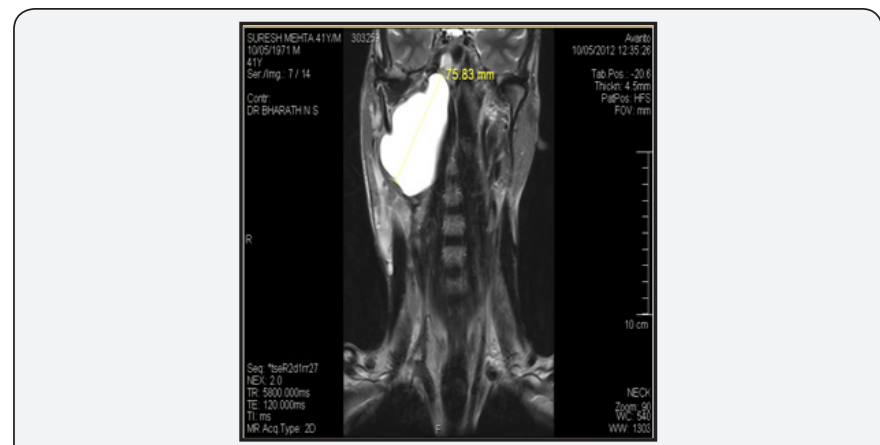

Figure 4: T2 weighted MRI coronal cut showing the full extent of right sided parapharyngeal lymphatic lesion.

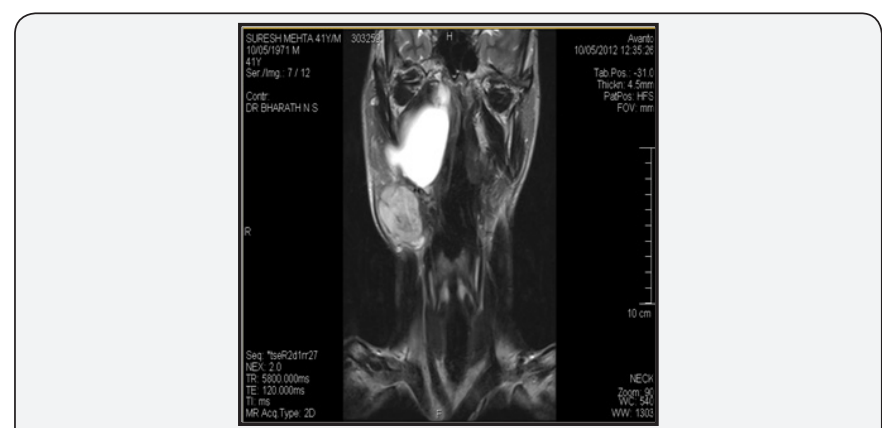

Figure 5: T2 weighted MRI coronal cut showing both the lesions with a definite plane between the two.

Under local infiltration, tracheostomy was done. Number 8 endotracheal tube was inserted and general anaesthesia was given. Skin crease incision was taken extending laterally from the angle of the jaw till the hyoid bone. Subplatysmal flaps elevated and the tortuous dilated external jugular vein was seen. Dissection extended medially and tumour encountered in the submandibular triangle. No separate plane existed between the submandibular gland and the tumour. Vascular mass along with the submandibular gland was removed Greater auricular nerve had to be divided to deliver the tumour.

On dissection of the posterior belly of digastric muscle, and on exposure of the parapharyngeal space, the inferior limit of the large lymphatic cyst was seen. There was a definite plane around the cyst which was separated by blunt dissection. Superiorly cyst was extending up to the jugular foramen. The cyst got ruptured in the process with expulsion of amber colored fluid. Almost the entire cyst wall was removed leaving a small remnant in the jugular foramen area. Malformed external jugular vein was decided to be left alone. After disinfection of the surgical field, the incision was closed in multiple layers over a suction drain. Number 8 portex cuffed tracheostomy tube was inserted.No-14 Ryles' tube was inserted.

Patient was nursed in Intensive care unit for 24 hours, drain was monitored. There was no fresh bleeding from the site. Ryles' tube feeds were started after 24 hours which was removed on $2 \mathrm{n}^{\mathrm{d}}$ day. Post operatively intravenous ceftriaxone was continued for 5 days. Drain was removed after 5 days. Patient was discharged from the hospital on 6th post operative day with tracheostomy tube. Sutures were removed on 8th day. Tracheostomy decanulation was done after 2 weeks by strapping method. Histopathological examination revealed a normal submandibular gland with a vascular malformation. The second specimen revealed lymphatic cyst. Patient is free of symptoms for the last 4 months' post operative period.

\section{Discussion}

In 1999, Sarteschi et al [2] first reported a case of right external jugular vein hemangioma occurring as a lateral neck mass. Mulliken and Glowacki, in 1982, [3] classified vascular lesions into two major groups: infantile hemangiomas and vascular malformations. Hemangiomas are characterized by endothelial cellular hyperplasia and proliferation, grow rapidly for 6-8 months after birth, and then regress to a variable extent. Vascular malformations have a normal endothelial cell cycle and do not involute. [1] Histologically vascular malformations show a normo cellular endothelium with normal cell cycle. They may have a combination of components capillary, venous and or lymphatic cells with or without fistulae, though majority are venous in nature [1].

Vascular malformations can be classified as high flow (arterio venous) and low flow malformations (Capillary, venous, lymphatic). They are painless, compressible, non pulsatile swellings most commonly present in neck. They usually have bluish tint on the overlying skin. They increase in size with valsalva manoeuvre and flattened by compression. The symptoms are due to location of malformations, thrombosis, pain being most common symptoms. Magnetic Resonance(MR) images of most of venous malformations are hypo intense in T1 weighted images 
and hyperintense in T2 weighted Images. MR angiogragraphy is indiacted if surgical removal is planned, also may be advised for academic purposes. Most of malformations do not require treatment if asymptomatic. Sclerotherapy has been advised, but there is a risk of necrosis of overlying skin.Surgical treatment is only advisable for easily accessible lesions and in those causing symptoms. Lympahtic malformations (LMs) are one of the rare conditions of lymphatic cysts. Usually seen in children and occasionally in adults. They vary from few millimeters to several centimeters in size.They are most commonly present in head and neck region. Neck lymphangiomas if large sized, can present with respiratory distress especially being cystic hygroma in new borns.

Parapharyngeal lymphatic cysts maybe congenital or acquired. Congenital lesions are due to failure of lymphatics to connect to venous system. Acquired cysts are due to obstruction of lymphatic flow either due to trauma or infection. The symptoms are due to compression of various structures in the complex parapharyngeal space. The presenting features maybe a diffuse neck swelling in post styloid lesions or oral swelling causing dysphagia and breathing difficulties in pre styloid lesions. Microscopically characterized by endothelially lined lymphatic cells. Usually LMs are congenital benign conditions [4]. CT delineates multicystic, homogenous, non invasive lesion . MR imaging remains the most definitive diagnostic modality for parapharyngeal cysts with hypo intense in T1 weighted and hyperintense in T2 weighted images. Spontaneous remission is rare. Enlargement of the lesion in later years has been noted. Surgical excision to be considered if presents with symptoms of obstruction. Radiation therapy has been tried with varying results [4]. Sclerotherapy as a primary mode of treatment can be done for subcutaneous lesions and the use of OK-432 have shown promising results in the treatment of unresectable lymphangiomas. Rupture of cyst wall with dissemination of sclerosant leading to fibrosis will make the subsequent surgery if needed, far more difficult [4].

\section{Conclusion}

The occurrence of vascular malformation of external jugular system with vascular tumour of submandibular gland and the occurrence of parapharyngeal lymphatic cyst is very rare. To the best of our knowledge no such articles are published in English language. Surgical removal is the most effective treatment option for symptomatic lymphatic swellings, even though other treatment modalities have been published. The vascular malformations need not be excised in patients who are asymptomatic.

\section{References}

1. Anil T, Ahuja, (2004) External Jugular Vein Vascular Malformation: Sonographic and MR Imaging Appearances. AJNR Am J Neuroradiol 25(2): 338-342.

2. Sarteschi LM, Bonanomi G, Mosca F, Ferrari M (1999) External jugular vein hemangioma occuring as a lateral neck mass. J Ultrasound Med 18(10): 719-721.

3. Mulliken JB, Glowacki J (1982) Hemangiomas and vascular malformations in infants and children: a classification based on endothelial characteristics. Plast Reconstr Surg 69: 412-422.

4. Marc Hamoir (2001) Lymphatic malformations of the head and neck: A retrospective review and a support for staging. Head \& Neck 23(4): 326-337.

\section{Your next submission with Juniper Publishers will reach you the below assets}

- Quality Editorial service

- Swift Peer Review

- Reprints availability

- E-prints Service

- Manuscript Podcast for convenient understanding

- Global attainment for your research

- Manuscript accessibility in different formats

( Pdf, E-pub, Full Text, Audio)

- Unceasing customer service

Track the below URL for one-step submission https://juniperpublishers.com/online-submission.php 